\title{
La vigilancia colonoscópica reduce la incidencia de cáncer colorrectal en pacientes con historia familiar y sindrome de Lynch
}

Isis Dove-Edwin, y col. BMJ 2005;331;1047

\section{Objetivo}

Determinar el beneficio de la vigilancia colonoscópica en pacientes con antecedentes familiares de cáncer colorrectal (CCR).

Diseño

Estudio observacional prospectivo.

\section{Lugar}

Clínica de cáncer en centro terciario de referencia en la ciudad de Londres.

\section{Pacientes}

1678 individuos de familias con Síndrome de Lynch (criterios de Amsterdam) o riesgo moderado (uno, dos o tres familiares afectados).

\section{Intervención}

Colonoscopía cada cinco años o cada tres, si era encontrado un adenoma.

\section{Medición de Resultados Principales}

Incidencia de adenoma de alto riesgo o cáncer, analizados en relación a la edad, afectación familiar y hallazgos en colonoscopías previas. Comparación de la incidencia y la mortalidad por CCR con índices esperados en individuos sin vigilancia.

\section{Resultados principales}

Los adenomas de alto riesgo y cáncer fueron mas frecuentes en familias con síndrome de Lynch (en colonoscopía inicial 5,7\% y $0,9 \%$, respectivamente). En familias de riesgo moderado estos hallazgos fueron infrecuentes antes de los 45 años $(1,1 \%$ y $0 \%)$ o si en la colonosocopía inicial no se había hallado un adenoma avanzado $(1,7 \%$ y $0,1 \%)$. La incidencia de CCR fue sustancialmente mas baja $(80 \%$, en familias con riesgo moderado y del $43 \%$, en familias con síndrome de Lynch [ $p<0,05]$ ) en relación a la incidencia esperada en ausencia de vigilancia.

\section{Conclusiones}

La vigilancia colonoscópica reduce el riesgo de CCR en familias con antecedente familiares de CCR. Se confirma que las familias con Síndrome de Lynch requieren vigilancia con intervalos cortos. Los individuos con menor cantidad de antecedentes podrían no requerir vigilancia hasta los 45 años y si no presentan adenomas avanzados en la colonocospía inicial, podría extenderse el intervalo.

Fuente de Financiamiento: North Thames Regional Health Authority Responsive Funding

\section{Comentario}

El $75 \%$ de los CCR se presentan en forma esporádica y luego de los 50 años. La vigilancia en la población de riesgo promedio (individuos mayores de 50 años sin antecedentes familiares) cuenta con múltiples estudios prospectivos y controlados que le dan alto nivel de evidencia a la efectividad de su aplicación. En 2005 se publicó una excelente revisón ${ }^{1}$. El otro grupo de pacientes con CCR es el de individuos con fami-liares afectados. Se estima que aproximadamente el 3 al $6 \%$ de los casos son formas hereditarias, de los cuales el Sidrome de Lynch representa su mayoría. Los criterios clínicos más difundidos para su diagnóstico son los criterios de Amsterdam (tres personas afectadas en la familia incluyendo dos generaciones y un afectado antes de los 50 años). La vigilancia en este grupo debe realizarse con colonoscopía desde los 20-25 años. En una reciente publicación se reporta un nivel de evidencia grado $\mathrm{B}^{\star}$ para su realización cada tres años ${ }^{2}$.

El tercer grupo de CCR lo representan las denominadas formas familiares que alcanzan el $20-25 \%$ de los casos. Estos individuos tienen antecedentes que no llegan a cumplimentar los criterios de
Amsterdam. La exposición a carcinogénicos comunes o la herencia de genes de baja penetrancia explicaría esta forma de presentación. Las actuales recomendaciones de las principales asociaciones discrepan en algunos detalles pero en general, recomiendan efectuar una colonoscopía a partir de los 40 años de vida ó diez años antes de la edad a la que se hizo diagnóstico en el familiar afectado y repetirla cada tres a cinco años, de acuerdo a los hallazgos. Sin embargo, la eficacia de esta estrategia no ha sido valorada en ningún estudio metodológicamente correcto.

\section{Conclusiones del comentador}

El presente estudio confirma que la vigilancia es efectiva para la prevención del CCR en individuos con historia familiar, aun si no cumplieran con los criterios de Amsterdam. Más importante aun, sugiere que la vi-gilancia en este grupo debería comenzarse a partir de los 45 o 50 años y que en ausencia de adenomas avanzados un intervalo mayor a cinco años puede ser adecuado.

Carlos Vaccaro [ Médico Cirujano, Especialista en Coloproctología. Hospital

* ver glosario

Vaccaro C. La vigilancia colonoscópica es eficaz para la reducción de la incidencia de cáncer colorrectal en pacientes con historia familiar y síndrome de Lynch. Evid. actual. práct. ambul; 9(1):12, Ene-Feb 2006. Comentado de: Dove-Edwin I, Sasieni P, Adams J, Thomas HJ. Prevention of colorectal cancer by colonoscopic surveillance in individuals with a family history of colorectal cancer: 16 year, prospective, follow-up study. BMJ. 2005 Nov 5; 331(7524):1047. PMID: 16243849 .

Referencias

1. Ransohoff D. Colon Cancer screening in 2005: Status and Challenges. Gastroenterology 2005; 128(6):1685-95

2. Johnson et al. Surveillance colonoscopy in individuals at risk for hereditary nonpolyposis colorectal cáncer. Dis Colon Rectum 2005;49:1-16.

\section{INFO - EVIDENCIA}

¿Qué es Evidencia, Actualización en la Práctica Ambulatoria?

Una publicación independiente editada cada dos meses desde 1997 por la Fundación MF, Organización sin fines de lucro dedicada promover el desarrollo de la medicina familiar y la atención primaria de la salud.

¿Cuál es el objetivo de Evidencia?

Contribuir a la educación continua y a la actualización de los profesionales de la salud de la región en el área de la atención ambulatoria. ¿Contenidos de Evidencia

- Información independiente, actualizada y resumida en forma sencilla y en castellano sobre temas relevantes de la atención ambulatoria.

Artículos seleccionados por su calidad y relevancia clínica, resumidos y comentados críticamente por destacados profesionales del área.

- Revisiones sobre temas clínicos, epidemiológicos, sanitarios o humanísticos, de importancia para la práctica ambulatoria.

Notas farmacológicas para la actualización rápida de temas de terapéutica clínica.

Discusión de casos clínicos con herramientas de Medicina Basada en la Evidencia.

Glosario de términos de epidemiología y medicina basada en la evidencia.

¿Cómo es posible acceder a Evidencia?

Por suscripción a la edición en papel, o bien por Intenet, en nuestro sitio:

http://www.evidencia.org 